ARTICLE HISTORY: Received: August: 6, 2021 Accepted: September 27, 2021 Published: October 4, 2021

\title{
STUDY OF THE INFLUENCE OF NON-EQUILIBRIUM EFFECTS ON OIL RECOVERY IN LAYERED FORMATIONS
}

\author{
Jalilova Rahima Qurban \\ Doctor of Philosophy in Physics and Mathematics, \\ Associate professor, Azerbaijan Pedagogical University \\ Azerbaijan,Baku
}

\section{ИССЛЕДОВАНИЕ ВЛИЯНИЯ НЕРАВНОВЕСНЫХ ЭФФЕКТОВ НА НЕФТЕОТДАЧУ В СЛОИСТЫХ ПЛАСТАХ.}

Джалилова Рахима Курбановна

\begin{abstract}
On the example of one problem, using the group-theoretic group theory, Ly's theory, the influence of unbalance effects on oil recovery in layered seams is investigated .

Резюме. На примере одной задачи с помощью теоретико-группового метода- теории Ли, исследуется влияние неравновесных эффектов на нефтеотдачу в слоистых пластах.

Key words: differensial equations, oil recovery, group analysis, unbalance effects, relaxation parameters, unlinear.

Ключевые слова: дифференциальные уравнения, нефтеотдача, групповые анализы, неравновесные эффекты, релаксационные параметры, нелинейные
\end{abstract}

Development of methods mathematics modeling for productioning oilfield ,growthing of hydrodynamic models of layer ,so creating of system automation project for working allowed the next step in the direction of determining and growthing of calculate optimal dynamic of extracting oil. For the production of oilfield there are the objective conditions of the creating different dynamic for extracting oil which consisting in being reserves of layer energy for intensification extracting oil in the first period of the production and so for the tehnical extent of resources artificial influence on the oil layers and racing from the layer.The main factors, which determining the dynamic and the levels of changing oil and liquid can divorce on geological, which characterize the collecor qualiies of layers and filling their fluids and the tehnology conditions of the production oilfields.

In this case the first group of factors in traditional flood is unregular:pervisity,porosity,viscosity of oil, configuration,mass expences and porosity of deposit,the first group is concerning to the manager parametres of the production oilfields:geometry and porosity of tuile wells, the system of placing of extract and supercharge wells, inflexions of pressure and ets. Different dynamic of extraction oil and corresponding tempo of the selection set in motion to different tehnico-economics indexes of the production. The dynamic of extracting oil is the unlinear on the stages of the intensive drilling of deposits and increasing of extraction oil, stabilization of extraction oil with influences on the layer, degradation of extraction oil ,emaciation of reserves oil and energy resourses of layer.

Submit for concideration the mathematics model of two-phases in the pit zone:

$$
\begin{aligned}
& \operatorname{diva}(x) \nabla p-c(x) \frac{\partial p}{\partial t}+\xi-\eta f=0(1) \\
& a(x)=k_{i}(\rho) / \mu_{i} x=\left(x_{1}, x_{2}\right), x \in \Omega \\
& c(x)=h(x)\left(m_{0} \beta_{\text {m }}+\beta_{\mathrm{m}}\right) p_{t=0}=p^{0} \\
& \vec{k}=\left(k_{1}, k_{2}\right), \vec{f}=\left(f_{1}, f_{2}\right) f_{\mathrm{i}}=k_{\mathrm{i}} /\left(\mu_{\mathrm{i}} a\right)
\end{aligned}
$$

$\mu_{i}$-viscosity, $k_{\mathrm{i}}$-relative pervious

$\mathrm{i}=1$ apply to oil , $\mathrm{i}=2$ to liquid, $\eta$-intensive of selection ,P-pressure,m-porosity ,

$x_{1}, x_{2}$-co-ordinates of plane ,t-time, J-нефтеотдача, $\mathrm{V}_{0}$-primary volume of oil in the layer, $\xi\left(x_{v} t\right)$-intensive of rolling up oil. 


$$
\begin{aligned}
& \int_{\Omega}(\xi-\eta) d x=0 \eta \geq 0(2) \\
& l=\int \frac{1}{\mathbb{v}_{0}} \int_{0}^{T} \int_{\Omega} \eta f_{1} d \vec{x} d t(3)
\end{aligned}
$$

T-time of production

Problem consist in definition of manager influences $\xi(x, t), \eta(x, t)$, which allow to get maximum нфтеотдача

$$
\int_{0}^{T} \int_{0} \eta d x d t=Q_{0}
$$

where $Q_{0}$-definite value

Assign the definite classes of decisions, finding which simpler than finding the general decision, we use theory Ly for it.

Construction the infinitesimal operator for the mission in the following view : (4)

$$
\begin{gathered}
x=\omega^{1}\left(x_{1}, x_{2}, t, p\right) \frac{\partial}{\partial x_{1}}+\omega^{2}\left(x_{1}, x_{2}, t, p\right) \frac{\partial}{\partial x_{2}}+\omega^{a}\left(x_{1}, x_{2}, t, p\right) \frac{\partial}{\partial t}+ \\
\omega^{4}\left(x_{1}, x_{2}, t, p\right) \frac{\partial}{\partial p}+v_{1} \frac{\partial}{\partial p_{x_{1}}}+v_{2} \frac{\partial}{\partial p_{x_{2}}}+v_{1} \frac{\partial}{\partial p_{t}}+v_{11} \frac{\partial}{\partial p_{x_{1} x_{1}}}+ \\
v_{12} \frac{\partial}{\partial p_{x_{1} x_{2}}}+v_{22} \frac{\partial}{\partial p_{x_{2} x_{2}}}+v_{19} \frac{\partial}{\partial p_{x_{1}}}+v_{21} \frac{\partial}{\partial p_{x_{2} \mathrm{e}}}+v_{\mathrm{ag}} \frac{\partial}{\partial p_{12}}
\end{gathered}
$$

In result of the action of the operator we get the next differencial equation:(5)

$$
\begin{gathered}
a\left(x_{1}, x_{2}\right)\left(v_{11}+v_{22}\right)+P_{x_{1} x_{1}} a_{x_{1}}\left(x_{1}, x_{2}\right) \omega^{1}+P_{x_{2} x_{2}} a_{x_{2}}\left(x_{1}, x_{2}\right) \omega^{2} \\
+P_{x_{1}} a_{x_{1} x_{1}}\left(x_{1}, x_{2}\right) \omega^{1}+P_{x_{2}} a_{x_{2} x_{2}}\left(x_{1}, x_{2}\right) \omega^{2}+a_{x_{1}}\left(x_{1}, x_{2}\right) v_{1}+ \\
a_{x_{2}}\left(x_{1}, x_{2}\right) v_{2}-c\left(x_{1}, x_{2}\right) v_{1}-P_{t} c_{x_{1}}\left(x_{1}, x_{2}\right) \omega^{1}- \\
P_{t} c_{x_{2}}\left(x_{1}, x_{2}\right) \omega^{2}=Q_{\mathrm{t}} \omega^{\mathrm{a}} \text { where } v_{11} \text { и } v_{22} \text { express in full differencial D with formulas: } \\
v_{11}=D_{x_{1}}\left(v_{1}\right)-p_{t x_{11}} D_{x_{1}}\left(\omega^{3}\right)-P_{x_{1} x_{1}} D_{x_{1}}\left(\omega^{1}\right)-P_{x_{2} x_{1}} D_{x_{1}}\left(\omega^{2}\right) \\
v_{22}=D_{x_{2}}\left(v_{2}\right)-p_{t x_{2}} D_{x_{2}}\left(\omega^{a}\right)-P_{x_{2} x_{1}} D_{x_{2}}\left(\omega^{1}\right)-P_{x_{2} x_{2}} D_{x_{2}}\left(\omega^{2}\right)
\end{gathered}
$$

In order to define a view function, $\omega^{1}\left(x_{1}, x_{2}, t, p\right), \omega^{2}\left(x_{1}, x_{2}, t, p\right), \omega^{4}\left(x_{1}, x_{2}, t, p\right)$ it is necessary with reckoning expressions for $v_{11}, v_{22}, v_{1}, v_{2}, v_{3}$ to split the definite equation, which is differencial concerning of unknown co-ordinates $\omega^{1}{ }_{s} \omega^{2}{ }_{r} \omega^{\mathrm{a}}{ }_{\mathrm{r}} \omega^{4}$.It is necessary to mark if do not use with the infinetizimal create of invariancy differencial equation and the formula substitute into the equation, in this case receiving system will be unlinear,if the first equation is unlinear,and ,mission of finding group will seem very complex and unwieldy. The definition equations always unlinear it means the application of the infinitesimal creates of invariancy actually do unlinear the mission of finding group of the transformation with permissible system of the differensial equations.

Splitting the equation (5) concerning "free" co-ordinate $\mathrm{P}$ and its derivatives, we get:

$$
\left.\begin{array}{l}
a \omega_{p}^{4}-2 a \omega_{x_{1}}^{1}+a_{x_{1}} \omega^{1}=0, \omega_{p}^{1}=0, \omega_{p}^{\mathrm{a}}=0, \omega_{x_{2}}^{\mathrm{a}}=0 \\
a \omega_{p}^{4}-2 a \omega_{x_{2}}^{2}+a_{x_{2}} \omega^{2}=0, \omega_{p}^{2}=0, \omega_{x_{1}}^{\mathrm{a}}=0, \omega_{p p}^{4}=0
\end{array}\right\}
$$




$$
\begin{aligned}
& \left.\begin{array}{l}
c \omega_{p}^{4}+c \omega_{t}^{3}-\omega^{1} c_{x_{1}}-\omega^{2} c_{x_{2}}=0 \\
-c \omega_{t}^{4}+a \omega_{x_{1} x_{1}}^{4}+a \omega_{x_{2} x_{2}}^{4}+a_{x_{1}} \omega_{x_{1}}^{4}+a_{x_{2}} \omega_{x_{2}}^{4}-\omega^{3} Q+
\end{array}\right\} \xi_{x_{1}}+\eta_{x_{1}} f+\xi_{x_{2}}+\xi_{x_{2}} f=0(6) \\
& \left.c \omega_{t}^{1}+2 a \omega_{x_{1} p}^{4}-a \omega_{x_{1} x_{1}}^{1}-a \omega_{x_{2} x_{2}}^{1}+a_{x_{1} x_{1}} \omega^{1}-a_{x_{1}} \omega_{x_{1}}^{1}-a_{x_{2}} \omega_{x_{2}}^{1}+\right) \\
& a_{x_{1}} \omega_{p}^{4}=0 \\
& \left.c \omega_{t}^{2}+2 a \omega_{x_{2} p}^{4}-a \omega_{x_{2} x_{2}}^{2}-a \omega_{x_{1} x_{1}}^{2}+a_{x_{2} x_{2}} \omega^{2}-a_{x_{1}} \omega_{x_{1}}^{2}-a_{x_{2}} \omega_{x_{2}}^{2}+\right\} \\
& a_{x_{2}} \omega_{p}^{4}=0
\end{aligned}
$$

It is possible to decide the mission of the group classification concerning element $\eta=\eta(x)$.Proposition about the arbitrary $\eta=\eta(x)$ and its derivative is made in receiving definition equations, that assists to additional splitting system (6) and give us the definition equations of nucleus of main groups.

$$
\left.\begin{array}{l}
\xi \omega_{p x_{1}}^{4}+\xi \omega_{x_{1} x_{1}}^{1}+c \omega_{t}^{1}-\xi \omega_{x_{2} x_{2}}^{1}-\xi_{x_{2}} \omega_{x_{2}}^{1}=0 \\
\eta \omega_{p x_{2}}^{4}+\eta \omega_{x_{2} x_{2}}^{2}+c \omega_{t}^{2}-\eta \omega_{x_{1} x_{1}}^{2}-\eta_{x_{2}} \omega_{x_{1}}^{2}=0
\end{array}\right\}
$$

After unheavy transformations we get the following treatments:

$$
\omega_{p}^{4}=\omega_{t}^{3} ; \omega_{x_{1} x_{1}}^{1}=0 ; \omega_{x_{2} x_{2}}^{2}=0
$$

The following equations appear in view of definite receiving system, which keep only $\eta(x)$.These equations are classifications:

$$
\omega^{2}=\left(\frac{\eta}{\eta_{x_{2}}}\right)\left(2 \omega_{x_{2}}^{2}-\omega_{t}^{a}\right) ; \omega^{1}=\left(\frac{\eta}{n_{x_{1}}}\right)\left(2 \omega_{x_{1}}^{1}-\omega_{t}^{a}\right)(7)
$$

We get some expanse of vector fields of tangent to groups for each decision of classification equations. We see the addition base of the main expanse till the base of expanse $L(\eta)$ ).

The main group is generated with transformations, which belong to 5 groups:

$$
\begin{gathered}
X_{1}=x_{1} \frac{\partial}{\partial x_{1}}+x_{2} \frac{\partial}{\partial x_{2}}+t \frac{\partial}{\partial t}, X_{2}=\frac{\partial}{\partial x_{1}}, X_{2}=\frac{\partial}{\partial x_{2}}, X_{4}=\frac{\partial}{\partial t^{x}} \\
X_{5}=\frac{\partial}{\partial p}
\end{gathered}
$$

It is possible to get the invariancy decision for each of these .It is interesting the chance of submiting the operators $\mathrm{X}_{2}$ и $\mathrm{X}_{3}$.For $\mathrm{X}_{2}$ corresponds the invariancy decision $\mathrm{p}=\mathrm{p}\left(\mathrm{x}_{2} \mathrm{t}\right)$,putting up in (1) we get:

$$
\frac{\partial}{\partial x_{2}}\left[\eta\left(x_{2}\right) \frac{\partial p}{\partial x_{2}}\right]-c \frac{\partial p}{\partial t}=Q(t)
$$

The receiving equation represents the single-measure equation of heat-conducting with variable coefficient and source, so the appling of theory Ly gave us the splitting of the first equation in directions $\mathrm{x}_{1}$ and $\mathrm{x}_{2}$.

When we use operator $\mathrm{X}_{3}$, we get:

$$
\frac{\partial}{\partial x_{1}}\left[\eta\left(x_{1}\right) \frac{\partial p}{\partial x_{1}}\right]-c \frac{\partial p}{\partial t}=Q(t)
$$

We can begin the classification.The main base is found ,the group of equivalent of equation is looked for in the class of equations, joining with condition,so as arbitrary $\eta$ depended on from $\mathrm{x}_{2}\left(\right.$ or from $\left.\mathrm{x}_{1}\right)$. 
equation:

When we difference the first equation in (7) on $\mathrm{x}_{2}$, but the second on $\mathrm{x}_{1}$, we get the following classification

$$
\left(\frac{\eta}{\eta_{x_{2}}}\right)_{x_{2} x_{2}}=0\left(\frac{\eta}{n_{x_{1}}}\right)_{x_{1} x_{1}}=0
$$

The decisions is written in that view :

$$
\frac{\eta_{\eta}}{\eta_{x_{2}}}=\frac{x_{2}}{r_{1}}+r_{2} ; \frac{\eta_{\eta}}{\eta_{x_{1}}}=\frac{x_{1}}{q_{1}^{\prime}}+r_{2}^{f} \text {, где } r_{1}, r_{2}, r_{1}^{f}, r_{2}^{f} \text {-const }
$$

The linear combination of invariant decisions of the main base of the group transformations are the invariancy decision too .Then the general decision of the classification system is noted in following view:

$$
\eta(x)=c_{1} x_{1}^{\alpha}+c_{2} x_{2}^{\beta}, \text { где } \alpha=\frac{1}{v_{1}}, \beta=\frac{1}{v_{1}^{\prime}}
$$

In that case we see the widening of the main group on vectors: $\left(\alpha x_{1}, \beta x_{2}, 0,2 p\right)$

The cultivate method of synthesis and approach of the group analysis of the differensial equations and the counting analysis reveals the good possibilities and allows to reseach numerous unlinear appearances, and the management influence, which influence on the productivity of layer.

\section{Literature}

[1].G.A.Virnovski ,E.I.Levitan, About identification of two-measure model of current of homogeneous liquid in porosity space. J.V.M. And M.F.T.XXX,№5,M.1990.

[2].L.V.Ovsannikov.The group analysis of differencial equations,M.1978.

3.R.G.Jalilova, S.Yu.Kasumov, K.F.Shirinov. The application of theory Ly to reseaching of single class for prosesses of filtration. News AN Azerb. Seriya f.t..and m.n.,№5-6,B.1995 